\title{
PENGARUH MODIFIKASI WAKTU PENGAPIAN TERHADAP UNJUK KERJA DAN EMISI GAS BUANG MESIN BENSIN DENGAN VARIASI CAMPURAN BAHAN BAKAR PREMIUM DAN BIOETANOL
}

\author{
Ricko Yudhanta, ST, M.Sc \\ Dosen STTD \\ JI. Raya Setu No. 89, Bekasi \\ Telp./Fax : (021) 8254640
}

\author{
Sumantri W. Praja, ST, M.Sc \\ Dosen STTD \\ Jl. Raya Setu No. 89, Bekasi \\ Telp./Fax : (021) 8254640
}

\author{
Drs. Ujang Cahyono, MM \\ Dosen STTD \\ Jl. Raya Setu No. 89, Bekasi \\ Telp./Fax : (021) 8254640
}

\author{
Ir. Tonny C. Korah, M.Si \\ Dosen STTD \\ Jl. Raya Setu No. 89, Bekasi \\ Telp./Fax : (021) 8254640
}

\author{
Arief Apriyanto, A.Ma.PKB, ST \\ Instruktur STTD \\ Jl. Raya Setu No. 89, Bekasi \\ Telp./Fax : (021) 8254640
}

\begin{abstract}
With the heat energy as an energy producer, it is necessary to require fuel and a combustion system that occurs as a source of heat. Related to the increase in the number of vehicles that mostly use fuel oil, thus triggering an increasing amount of demand and increasing fuel use, this is contrary to the availability of oil in the bowels of the earth which is running low. Therefore it is necessary to think in designing an engine with high efficiency. The addition of bioethanol to premium is able to produce better exhaust emissions (lower $\mathrm{CO}$ and HC content) than emissions produced by pure premium fuels. The results of the gasoline engine exhaust emissions test are influenced by the reading of the $\mathrm{CO}$ (Carbon Monoxide) and HC (Hydro Carbon) sensors. At $8000 \mathrm{rpm}$ engine speed in all variations of the ignition time, $\mathrm{CO}$ concentration showed the highest number. In the variation of ignition time 100 and 120 before TMA the CO value produced was 4.56 vol\% and $6.44 \%$ vol, exceeding the specified threshold of $4.5 \%$ vol. CO levels decrease below the threshold in the engine speed range of 3000 to $7500 \mathrm{rpm}$. The lowest $\mathrm{HC}$ level of $62.45 \mathrm{ppm}$ vol occurred at the ignition time 80 before TDC at $6500 \mathrm{rpm}$ engine speed. At medium engine speed (5000 to $6500 \mathrm{rpm}$ ), HC emissions have decreased significantly. This is because the mixture of air and fuel approaches stoichiometric with the use of $E 10$ fuel variations. Thus, the fuel turns into gas, making it easy to burn in the combustion chamber. The highest torque value of $0.83 \mathrm{kgf.m}$ occurs at the ignition time of 120 before TDC at $5000 \mathrm{rpm}$ engine speed. In the engine speed range of 5000 to $6000 \mathrm{rpm}$ in all variations of ignition there is an increase in torque. This is because the temperature of the mixture of air and fuel is achieved at each ideal ignition time at rotation of 5000 to $6000 \mathrm{rpm}$, so that the maximum torque produced. The highest power value of 7.63 PS occurs at the time of ignition 120 before TDC at $7500 \mathrm{rpm}$ engine speed. The use of the $E 10$ fuel variation affects engine performance by increasing the fuel temperature at the intake manifold, so that the mixture of air and fuel can turn into gas, so that fuel entering the combustion chamber becomes optimal and produces a large $P$ (explosion) power.
\end{abstract}

Keywords: Motorcycle, Fuel, Testing, Premium, Bioethanol, Emissions, Torque, Power, Air Pollution, Exhaust Gas, CO, HC 


\begin{abstract}
ABSTRAKSI
Dengan adanya energi kalor sebagai suatu penghasil tenaga maka sudah semestinya memerlukan bahan bakar dan sistem pembakaran yang terjadi sebagai sumber kalor tersebut. Berkaitan dengan kenaikan jumlah kendaraan yang sebagian besar menggunakan bahan bakar minyak, sehingga memicu jumlah kenaikan permintaan serta penggunaan bahan bakar yang semakin meningkat, hal ini bertolak belakang dengan ketersediaan minyak di dalam perut bumi yang semakin menipis. Oleh karena itu perlu adanya pemikiran dalam mendisain suatu engine dengan efisiensi yang tinggi. Penambahan bioetanol pada premium mampu menghasilkan emisi gas buang yang lebih baik (kandungan $\mathrm{CO}$ dan HC yang lebih rendah) daripada emisi yang dihasilkan oleh bahan bakar premium murni. Hasil dari uji emisi gas buang mesin bensin salah satunya dipengaruhi oleh pembacaaan dari sensor $\mathrm{CO}$ (Carbon Monoksida) dan HC (Hidro Carbon). Pada putaran mesin $8000 \mathrm{rpm}$ di semua variasi waktu pengapian, konsentrasi CO menunjukkan angka tertinggi. Dalam variasi waktu pengapian $10^{\circ}$ dan $12^{\circ}$ sebelum TMA nilai CO yang dihasilkan yaitu 4,56\%vol dan 6,44 \%vol, melebihi ambang batas yang ditentukan sebesar 4,5 \%vol. Kadar CO semakin menurun di bawah ambang batas pada range putaran mesin 3000 sampai $7500 \mathrm{rpm}$. Kadar HC terendah sebesar 62,45 ppm vol terjadi pada waktu pengapian $8^{0}$ sebelum TMA di putaran mesin $6500 \mathrm{rpm}$. Pada putaran mesin menengah (5000 s/d $6500 \mathrm{rpm})$, emisi HC mengalami penurunan yang signifikan. Hal ini disebabkan karena campuran udara dan bahan bakar mendekati stoichiometric dengan adanya penggunaan variasi bahan bakar $\mathrm{E}_{10}$. Sehingga, bahan bakar berubah fasenya menjadi gas, maka mudah untuk terbakar di ruang bakar. Nilai torsi tertinggi sebesar $0,83 \mathrm{kgf} . \mathrm{m}$ terjadi pada waktu pengapian $12^{0}$ sebelum TMA di putaran mesin $5000 \mathrm{rpm}$. Pada range putaran mesin $5000 \mathrm{~s} / \mathrm{d} 6000 \mathrm{rpm}$ di semua variasi pengapian terdapat peningkatan torsi. Hal ini dikarenakan temperatur campuran udara dan bahan bakar yang tercapai pada masing-masing waktu pengapian ideal pada putaran $5000 \mathrm{~s} / \mathrm{d} 6000 \mathrm{rpm}$, sehingga torsi yang dihasilkan maksimal. Nilai daya tertinggi sebesar 7,63 PS terjadi pada waktu pengapian $12^{0}$ sebelum TMA di putaran mesin $7500 \mathrm{rpm}$. Penggunaan variasi bahan bakar $\mathrm{E}_{10}$ berpengaruh terhadap kinerja mesin dengan meningkatkan temperatur bahan bakar pada intake manifold, sehingga campuran udara dan bahan bakar dapat berubah menjadi gas, agar bahan bakar yang masuk ke dalam ruang bakar menjadi optimal dan menghasilkan daya P (ledakan) yang besar.
\end{abstract}

Kata kunci : Sepeda Motor, Bahan Bakar, Pengujian, Premium, Bioetanol, Emisi, Torsi, Daya, Pencemaran Udara, Gas Buang, CO, HC 


\section{PENDAHULUAN}

\section{Latar Belakang}

Kendaraan bermotor merupakan salah satu alat transportasi yang memerlukan engine sebagai penggerak mulanya, baik roda dua maupun roda empat. Motor bakar merupakan salah satu engine yang digunakan sebagai penggerak mula tersebut, yaitu merupakan suatu mesin konversi energi yang merubah energi kalor menjadi mekanik. Dengan adanya energi kalor sebagai suatu penghasil tenaga maka sudah semestinya memerlukan bahan bakar dan sistem pembakaran yang terjadi sebagai sumber kalor tersebut. Dalam hal ini bahan bakar yang sering digunakan dalam kendaraan adalah bensin dan solar. Berkaitan dengan kenaikan jumlah kendaraan yang sebagian besar menggunakan bahan bakar minyak sehingga memicu jumlah kenaikan permintaan serta penggunaan bahan bakar yang semakin meningkat, hal ini bertolak belakang dengan ketersediaan minyak di dalam perut bumi yang semakin menipis. Oleh karena itu perlu adanya pemikiran dalam mendisain suatu engine dengan efisiensi yang tinggi.

Uji Emisi Gas Buang merupakan salah satu persyaratan teknis laik jalan yang harus dipenuhi dari suatu kendaraan bermotor, cara pengukurannya sesuai dengan jenis mesin yang digunakan, yang memiliki metode uji berbeda berdasarkan Idle (Stationer) maupun Acceleration (Akselerasi), sehingga menghasilkan emisi yang ramah terhadap lingkungan. Hasil dari uji emisi gas buang mesin bensin salah satunya dipengaruhi oleh pembacaaan dari sensor CO (Carbon Monoksida), CO2 (Carbon Dioksida) dan HC (Hidro Carbon).

Berdasarkan permasalahan di atas, maka penulis akan mengadakan penelitian yang diharapkan dapat mengatasi hal tersebut yang tertuang dalam laporan "Pengaruh Modifikasi Waktu Pengapian Terhadap Unjuk Kerja dan Emisi Gas Buang Mesin Bensin dengan Variasi Campuran Bahan Bakar Premium dan Bioetanol”. 


\section{METODOLOGI PENELITIAN}

\section{Metode Pengumpulan Data}

Dalam melaksanakan penelitian, untuk memperoleh hasil yang baik maka diperlukan sejumlah data pendukung agar dapat dilakukan analisa data. Data yang dibutuhkan untuk penelitian ini berdasarkan dari data sekunder dan data primer.

Pengumpulan data dalam penelitian ini dilakukan melalui metode yang digunakan adalah dengan observasi lapangan dengan melakukan uji coba menggunakan sampel yang telah ditentukan yaitu kendaraan bermotor yang akan digunakan sebagai objek penelitian ini.

\section{Metode Penelitian}

Penelitian ini adalah penelitian eksperimen yang dilaksanakan di Laboratorium Pengujian dan Kontrol Kendaraan Bermotor, bertujuan untuk mengetahui sebab akibat yang muncul berdasarkan perubahan perlakuan peneliti. Perubahan perlakuan tersebut adalah pengaruh perubahan waktu pengapian $\left(8^{0}, 10^{0}, 12^{0}\right)$, komposisi campuran bahan bakar premium dengan bioetanol (E10), unjuk kerja mesin yang diukur dengan alat ukur Dyno Test, dan emisi gas buang pada sepeda motor 4 tak yang diukur menggunakan alat uji emisi gas buang Capelec 3201.

\section{Sampel Penelitian}

Dalam penelitian ini variabel bebas meliputi variasi waktu pengapian $8^{\circ}, 10^{\circ}$ dan $12^{\circ}$ sebelum TMA, dan variasi bahan bakar campuran bioetanol $10 \%+$ premium $90 \%\left(\mathrm{E}_{10}\right)$.

Variabel terikat meliputi torsi, daya efektif, dan kandungan emisi gas buang pada sepeda motor. Pada penelitian ini variabel kontrol meliputi : a) Sepeda motor 4 Tak 1 Silinder; b) Temperatur oli mesin 60-80 ${ }^{\circ} \mathrm{C}$ (temperatur kerja mesin); c) 
Variasi putaran mesin di rentang $3000 \mathrm{rpm}$ sampai dengan $8000 \mathrm{rpm}$ dengan range $500 \mathrm{rpm}$.

\section{Teknik Analisis Data}

Teknik analisis data yang digunakan dalam penelitian ini menggunakan metode statistika deskriptif. Hal ini dilaksanakan untuk memberikan gambaran terhadap fenomena yang terjadi setelah dilakukan beberapa perubahan waktu pengapian dari $8^{\circ}, 10^{\circ}$ (standar) dan $12^{\circ}$ sebelum TMA dengan variasi campuran bahan bakar premium dan bioetanol.

\section{Alat dan Bahan}

1. Alat-alat yang digunakan dalam penelitian ini adalah sebagai berikut:

a. Burret tester (Gelas Ukur), alat untuk menampung bahan bakar.

b. Stopwatch, untuk mengukur waktu.

c. Tachometer, untuk mengukur putaran mesin.

d. Blower, untuk menjaga suhu kerja mesin.

e. Emisi tester CAPELEC 3201, untuk menguji kandungan emisi gas buang. Dengan spesifikasi alat:

1) Power supply : $115-230 \mathrm{~V} 1,5 \mathrm{~A}$

2) Max consumption :70W

3) Measurement range : 0 to $99.9 \%$ res. 0,1

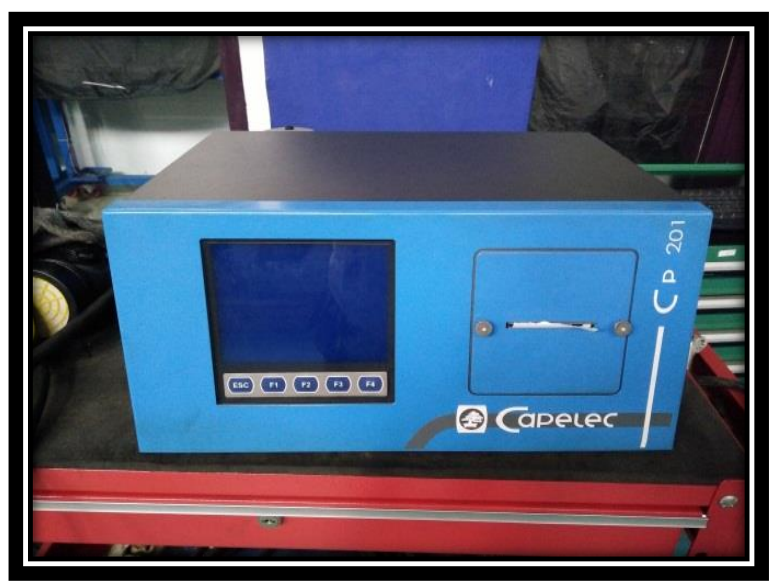




\section{Gambar 1. Alat Uji Emisi Gas Buang}

f. Chassis dynamometer HOFMANN, untuk menguji unjuk kerja (performa). Dengan spesifikasi teknis:

1) Max pressure air compressor :0,8-1,1 bar

2) Max consumption : $850-1100 \mathrm{~W}$

3) Measurement roller dyno : 0 to $99.9 \%$ corr. 0,1

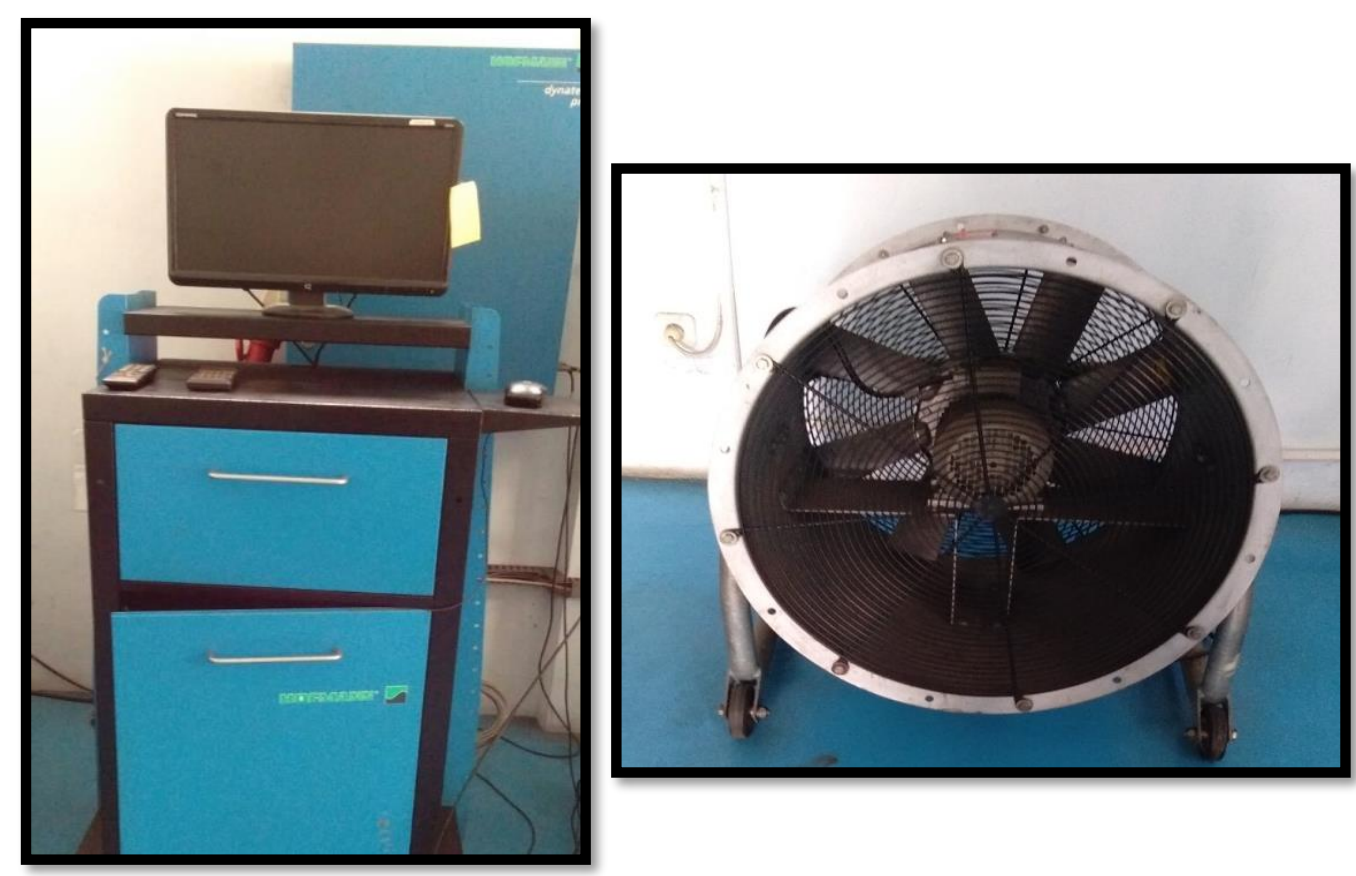

Gambar 2. Alat Uji Dyno Test

2. Bahan-bahan yang digunakan dalam penelitian ini adalah sebagai berikut:

a. Sepeda motor Honda Vario 2012, dengan spesifikasi :
1) Tipe mesin
: 4 Langkah SOHC
2) Sistem pendinginan
: Pendinginan dengan cairan
3) Diameter $x$ Langkah
: 57 x $55 \mathrm{~cm}$
4) Volume Langkah
: $124,5 \mathrm{cc}$
5) Perbandingan kompresi : 10,2:1
6) Sistem pengapian
: DC - CDI

b. Premium diperoleh dari pembelian di SPBU Cibitung. Bioetanol yang digunakan mempunyai grade $98 \%$ yang digunakan untuk bahan bakar. 


\section{Pelaksanaan Penelitian}

1. Mempersiapkan alat, bahan dan instrumen penelitian;

2. Melaksanakan tune up pada kendaraan agar berada pada kondisi yang optimal;

3. Memasang selang dari burret (gelas ukur) ke saluran masuk (intake) bahan bakar, kemudian isi dengan premium murni $\left(\mathrm{E}_{0}\right)$;

4. Menghidupkan blower untuk menjaga temperatur mesin;

5. Kendaraan dihidupkan dengan waktu \pm 3 menit, agar suhu kerja mesin mencapai optimal;

6. Menghidupkan alat emisi gas buang dan dyno test yang sudah diinstall pada kendaraan;

7. Melakukan pengukuran emisi gas buang dan dyno test sesuai prosedur penggunaan alat uji sebanyak dua kali, dengan putaran mesin dari rentang 3000 rpm hingga 8000 rpm;

8. Mencetak hasil pengukuran, dan menonaktifkan alat uji.

\section{HASIL DAN PEMBAHASAN}

\section{Hasil Eksperimen Rata-rata Konsentrasi CO (karbonmonoksida) dalam \%} volume

Dari hasil percobaan modifikasi waktu pengapian, maka diperoleh tabel nilai kandungan emisi $\mathrm{CO}$, adalah sebagai berikut:

Tabel 1. Hasil Eksperimen Rata-rata Konsentrasi CO dalam \% volume

\begin{tabular}{|c|c|c|c|}
\hline \multirow{2}{*}{ Putaran (rpm) } & \multicolumn{3}{|c|}{ Konsentrasi Karbonmonoksida (CO) } \\
\cline { 2 - 4 } & \multicolumn{3}{|c|}{ Hasil Eksperimen Rata-rata (\% vol) } \\
\cline { 2 - 4 } & $8^{\circ}$ sebelum TMA & $10^{\circ}$ sebelum TMA & $12^{\circ}$ sebelum TMA \\
\hline 3000 & 1.33 & 0.16 & 0.30 \\
\hline 3500 & 1.26 & 0.15 & 0.25 \\
\hline 4000 & 1.09 & 0.14 & 0.18 \\
\hline 4500 & 0.54 & 0.13 & 0.14 \\
\hline 5000 & 0.15 & 0.32 & 0.20 \\
\hline
\end{tabular}




\begin{tabular}{|l|l|l|l|}
\hline 5500 & 0.17 & 0.47 & 0.56 \\
\hline 6000 & 0.26 & 0.60 & 0.88 \\
\hline 6500 & 0.35 & 1.19 & 1.71 \\
\hline 7000 & 0.43 & 1.78 & 3.14 \\
\hline 7500 & 1.16 & 2.17 & 4.66 \\
\hline 8000 & 3.39 & 4.56 & 6.44 \\
\hline
\end{tabular}

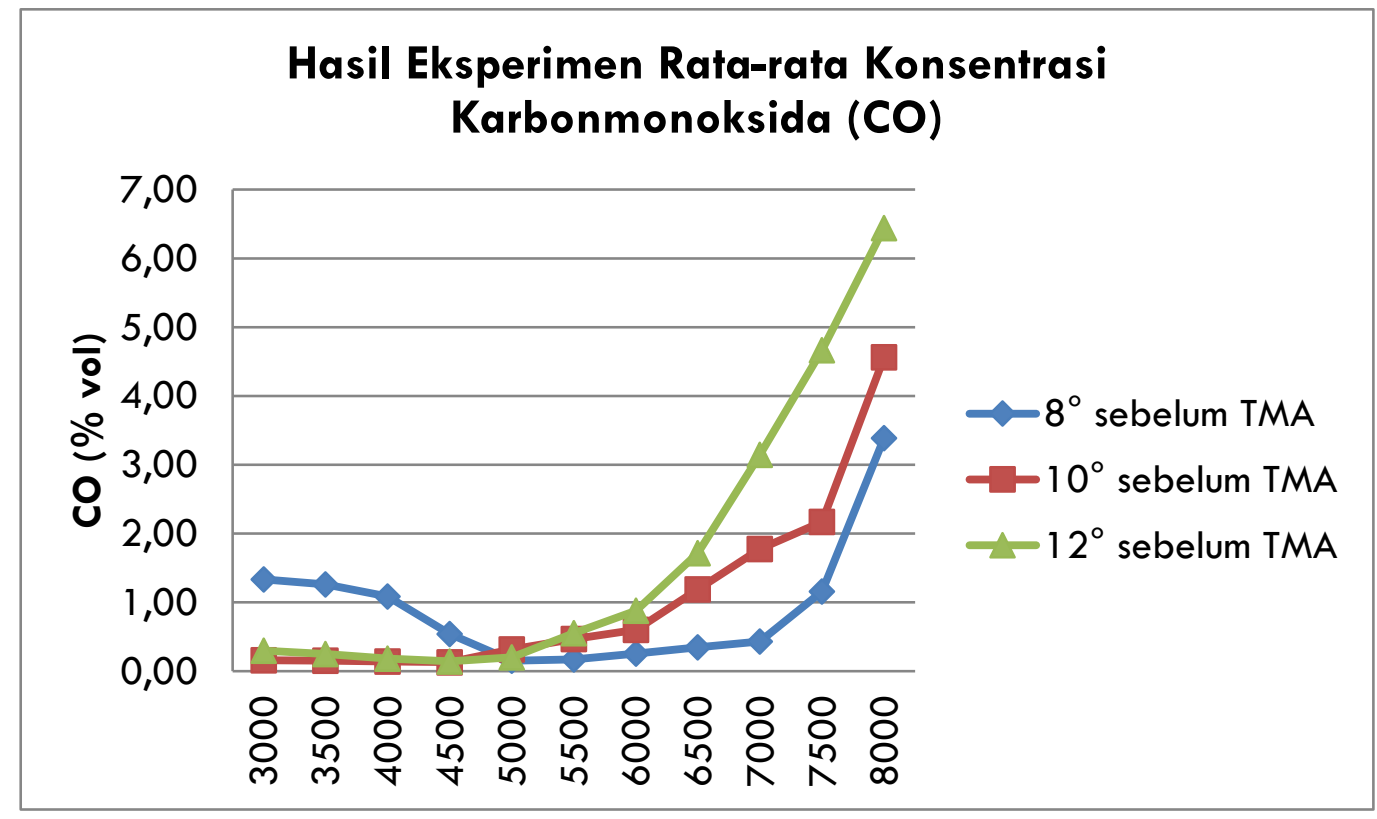

Gambar 3. Eksperimen Rata-rata Konsentrasi Karbonmonoksida (CO) dalam \% vol

Dengan memperhatikan grafik pada gambar 3, konsentrasi CO pada setiap variasi waktu pengapian mengalami perubahan seiring putaran mesin yang semakin meningkat. Pada putaran mesin 8000 rpm di semua variasi waktu pengapian, konsentrasi $\mathrm{CO}$ menunjukkan angka tertinggi. Pada variasi waktu pengapian $10^{\circ}$ dan $12^{0}$ sebelum TMA nilai CO yang dihasilkan yaitu 4,56\%vol dan 6,44 \%vol, melebihi ambang batas yang ditentukan sebesar 4,5\%vol. Kadar $\mathrm{CO}$ semakin menurun di bawah ambang batas pada range putaran mesin 3000 sampai $7500 \mathrm{rpm}$.

Hal ini menunjukkan, bahwa pada range putaran mesin 3000 sampai $7500 \mathrm{rpm}$ temperatur campuran udara dan bahan bakar menjadi lebih optimal, menyebabkan campuran tersebut menjadi gas dengan adanya penggunaan 
variasi bahan bakar $\mathrm{E}_{10}$, sehingga pembakaran menjadi sempurna dan emisi $\mathrm{CO}$ yang dikeluarkan dari kendaraan pada saat beroperasi tidak berbahaya.

\section{Hasil Eksperimen Rata-rata Konsentrasi $\mathrm{CO} 2$ (Karbondioksida) dalam \% vol}

Dari hasil percobaan modifikasi waktu pengapian, maka diperoleh tabel nilai kandungan emisi $\mathrm{CO}_{2}$, adalah sebagai berikut:

Tabel 2. Hasil Pengujian Kandungan Emisi $\mathrm{CO}_{2}$ dalam \% volume

\begin{tabular}{|c|c|c|c|}
\hline \multirow{2}{*}{ Putaran (rpm) } & \multicolumn{3}{|c|}{ Konsentrasi Karbondioksida (CO2) } \\
\cline { 2 - 4 } & \multicolumn{3}{|c|}{ Hasil Eksperimen Rata-rata (\% vol) } \\
\cline { 2 - 4 } & $8^{\circ}$ sebelum TMA & $10^{\circ}$ sebelum TMA & $12^{\circ}$ sebelum TMA \\
\hline 3000 & 11.24 & 10.98 & 11.05 \\
\hline 3500 & 11.89 & 12.39 & 12.27 \\
\hline 4000 & 11.72 & 11.64 & 11.81 \\
\hline 4500 & 12.09 & 12.64 & 12.61 \\
\hline 5000 & 12.32 & 12.62 & 13.26 \\
\hline 5500 & 12.81 & 13.25 & 12.99 \\
\hline 6000 & 13.28 & 13.05 & 12.05 \\
\hline 6500 & 13.54 & 13.39 & 10.57 \\
\hline 7000 & 13.65 & 12.91 & 9.92 \\
\hline 7500 & 12.50 & 12.67 & 9.40 \\
\hline 8000 & 11.13 & 10.89 & \\
\hline
\end{tabular}




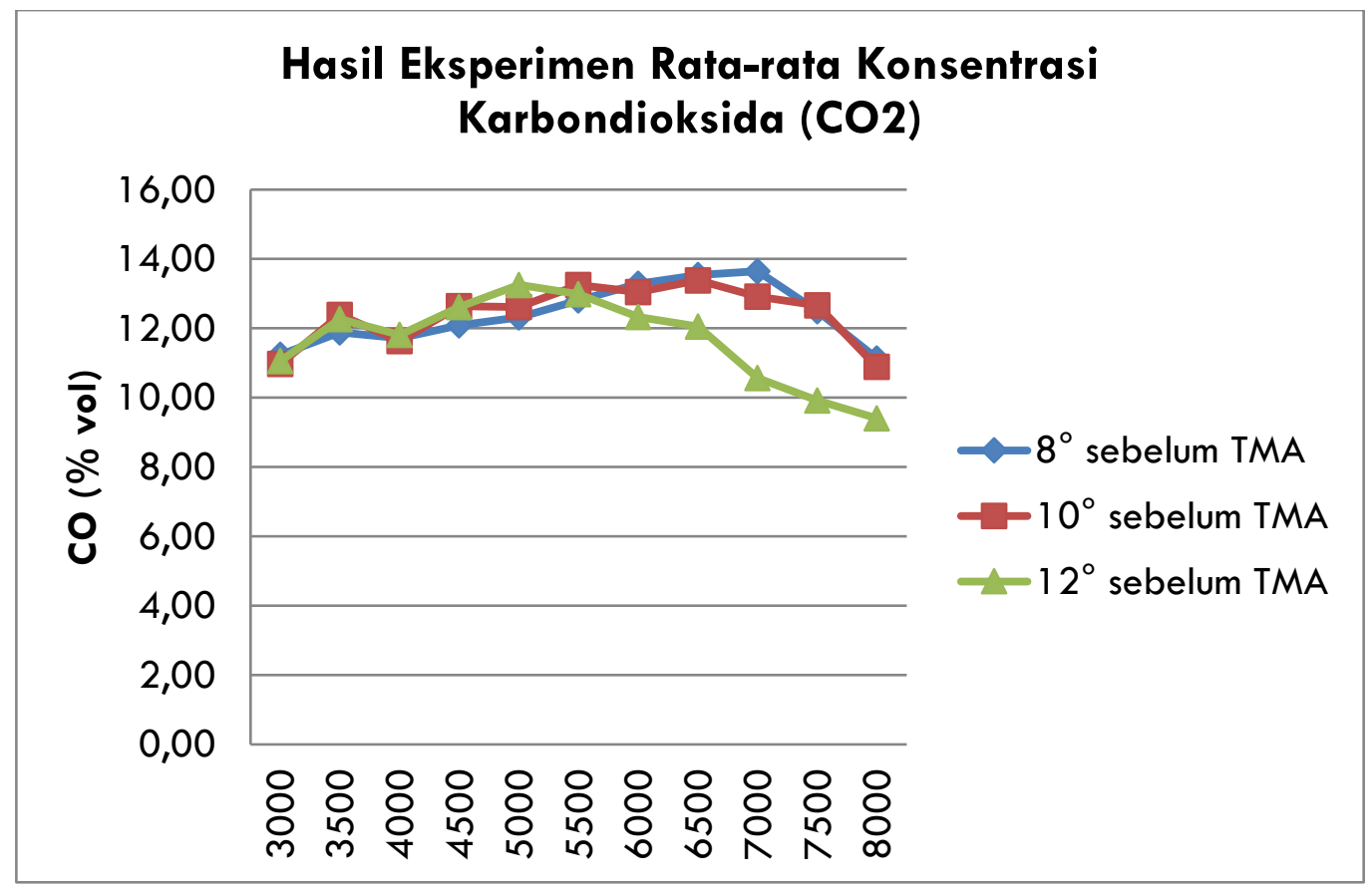

Gambar 4. Grafik Hasil Eksperimen Rata-rata Konsentrasi Karbondioksida (CO2) dalam \% vol

Memperhatikan grafik yang ada pada gambar 4, konsentrasi $\mathrm{CO}_{2}$ pada setiap variasi waktu pengapian mengalami perubahan seiring putaran mesin yang semakin meningkat. Kadar $\mathrm{CO}_{2}$ terendah sebesar 9,40 \%vol terjadi pada waktu pengapian $12^{0}$ sebelum TMA di putaran mesin $8000 \mathrm{rpm}$.

Kenaikan putaran mesin mempercepat proses pembakaran, maka bahan bakar yang terbakar relatif lebih banyak dan konsentrasi $\mathrm{CO}_{2}$ cenderung semakin kecil. Hal tersebut dikarenakan penggunaan variasi bahan bakar $\mathrm{E}_{10}$.

Sehingga, temperatur pada intake manifold menjadi naik menyebabkan campuran udara dan bahan bakar yang berada di dalam ruang bakar juga naik temperaturnya. Mengakibatkan campuran udara dan bahan bakar cenderung menjadi gas, sehingga ketika masuk ke ruang bakar campuran udara dan bahan bakar menjadi siap dan mudah untuk dibakar. 
3. Hasil Eksperimen Rata-rata Konsentrasi HC (Hidrokarbon) dalam ppm vol

Dari hasil percobaan modifikasi waktu pengapian, maka diperoleh tabel nilai kandungan emisi HC, sebagai berikut:

Tabel 3. Hasil Eksperimen Rata-rata Konsentrasi Hidrokarbon (HC) dalam ppm vol

\begin{tabular}{|c|c|c|c|}
\hline \multirow{2}{*}{ Putaran (rpm) } & \multicolumn{4}{|c|}{ Konsentrasi Hidrokarbon (HC) } \\
\cline { 2 - 4 } & \multicolumn{3}{|c|}{ Hasil Eksperimen Rata-rata (ppm vol) } \\
\cline { 2 - 4 } & $8^{\circ}$ sebelum TMA & $10^{\circ}$ sebelum TMA & $12^{\circ}$ sebelum TMA \\
\hline 3000 & 483.73 & 338.15 & 336.82 \\
\hline 3500 & 470.84 & 257.08 & 243.97 \\
\hline 4000 & 297.38 & 232.36 & 228.17 \\
\hline 4500 & 283.50 & 123.59 & 142.24 \\
\hline 5000 & 120.93 & 84.04 & 130.38 \\
\hline 5500 & 118.95 & 72.18 & 119.52 \\
\hline 6000 & 77.32 & 75.15 & 117.54 \\
\hline 6500 & 62.45 & 91.95 & 103.71 \\
\hline 7000 & 74.34 & 112.72 & 143.22 \\
\hline 7500 & 98.13 & 115.68 & 170.88 \\
\hline 8000 & 149.68 & 139.41 & 179.77 \\
\hline
\end{tabular}

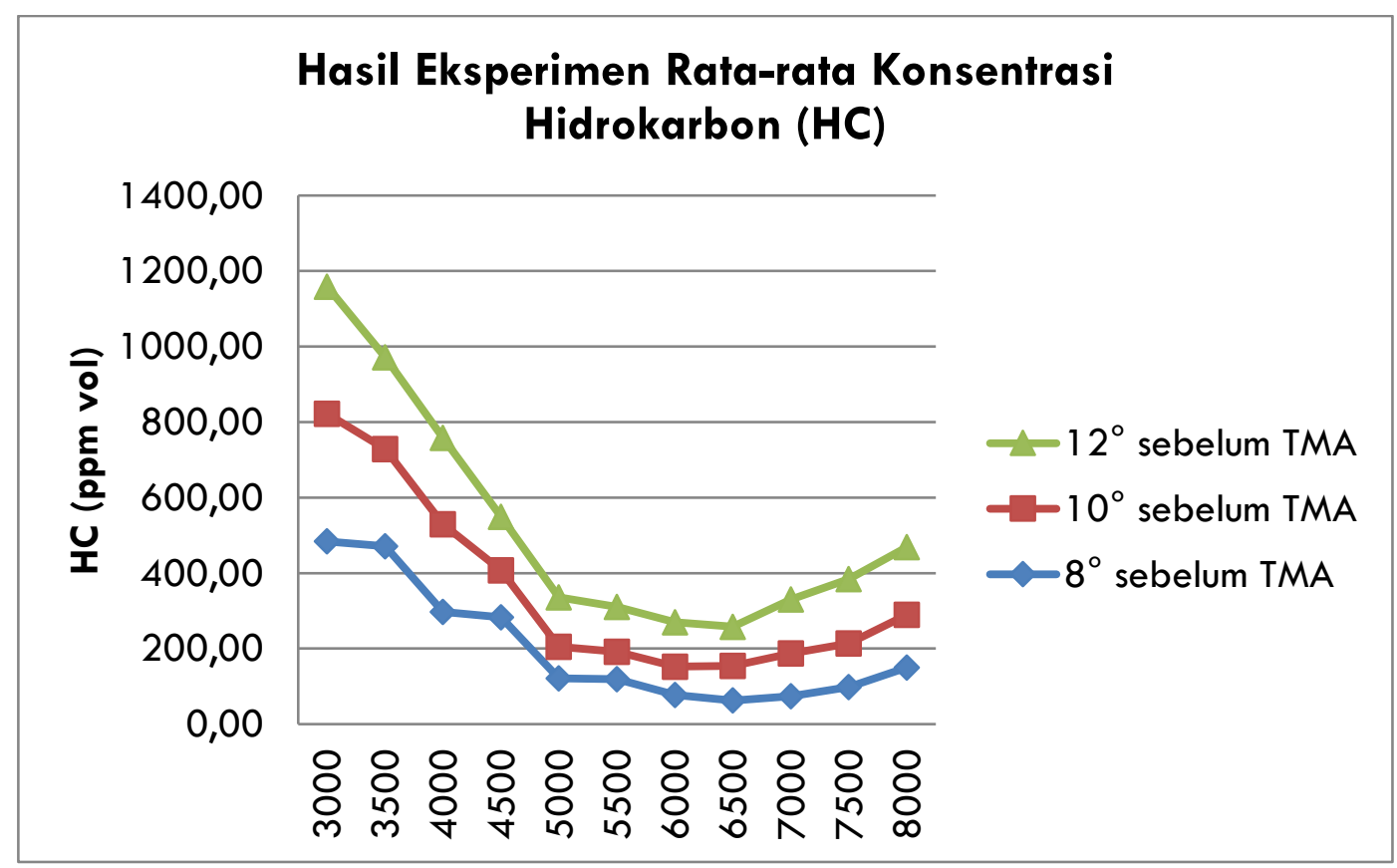

Gambar 5. Grafik Hasil Pengujian Kandungan Emisi HC dalam ppm volume 
Dengan memperhatikan grafik pada gambar 5, konsentrasi HC pada setiap variasi waktu pengapian mengalami perubahan seiring putaran mesin yang semakin meningkat. Kadar HC terendah sebesar 62,45 ppm vol terjadi pada waktu pengapian $8^{0}$ sebelum TMA di putaran mesin $6500 \mathrm{rpm}$.

Pada putaran mesin menengah (5000 s/d 6500 rpm), emisi HC mengalami penurunan yang signifikan. Hal ini disebabkan karena campuran udara dan bahan bakar mendekati stoichiometric dengan adanya penggunaan variasi bahan bakar $\mathrm{E}_{10}$. Sehingga, bahan bakar berubah fasenya menjadi gas, maka mudah untuk terbakar di ruang bakar.

\section{Hasil Eksperimen Rata-rata Konsentrasi O2 (Oksigen) dalam \% vol}

Dari hasil percobaan modifikasi waktu pengapian, maka diperoleh tabel nilai Oksigen $\left(\mathrm{O}_{2}\right)$, adalah sebagai berikut:

Tabel 4. Hasil Eksperimen Rata-rata Konsentrasi Oksigen $\left(\mathrm{O}_{2}\right)$ dalam \%vol

\begin{tabular}{|c|c|c|c|}
\hline \multirow{2}{*}{ Putaran (rpm) } & \multicolumn{3}{|c|}{ Konsentrasi Oksigen (O2) } \\
\cline { 2 - 4 } & \multicolumn{3}{|c|}{ Hasil Eksperimen Rata-rata (\% vol) } \\
\cline { 2 - 4 } & $8^{\circ}$ sebelum TMA & $10^{\circ}$ sebelum TMA & $12^{\circ}$ sebelum TMA \\
\hline 3000 & 2.94 & 4.46 & 4.89 \\
\hline 3500 & 2.72 & 4.07 & 2.84 \\
\hline 4000 & 2.87 & 3.25 & 2.82 \\
\hline 4500 & 2.45 & 2.62 & 2.17 \\
\hline 5000 & 2.18 & 3.10 & 1.10 \\
\hline 5500 & 2.55 & 1.95 & 1.46 \\
\hline 6000 & 1.78 & 1.94 & 0.50 \\
\hline 6500 & 1.68 & 1.24 & 1.15 \\
\hline 7000 & 0.88 & 0.64 & 0.70 \\
\hline 7500 & 0.93 & 0.61 & 0.58 \\
\hline 8000 & 0.99 & 2.05 & 1.74 \\
\hline
\end{tabular}




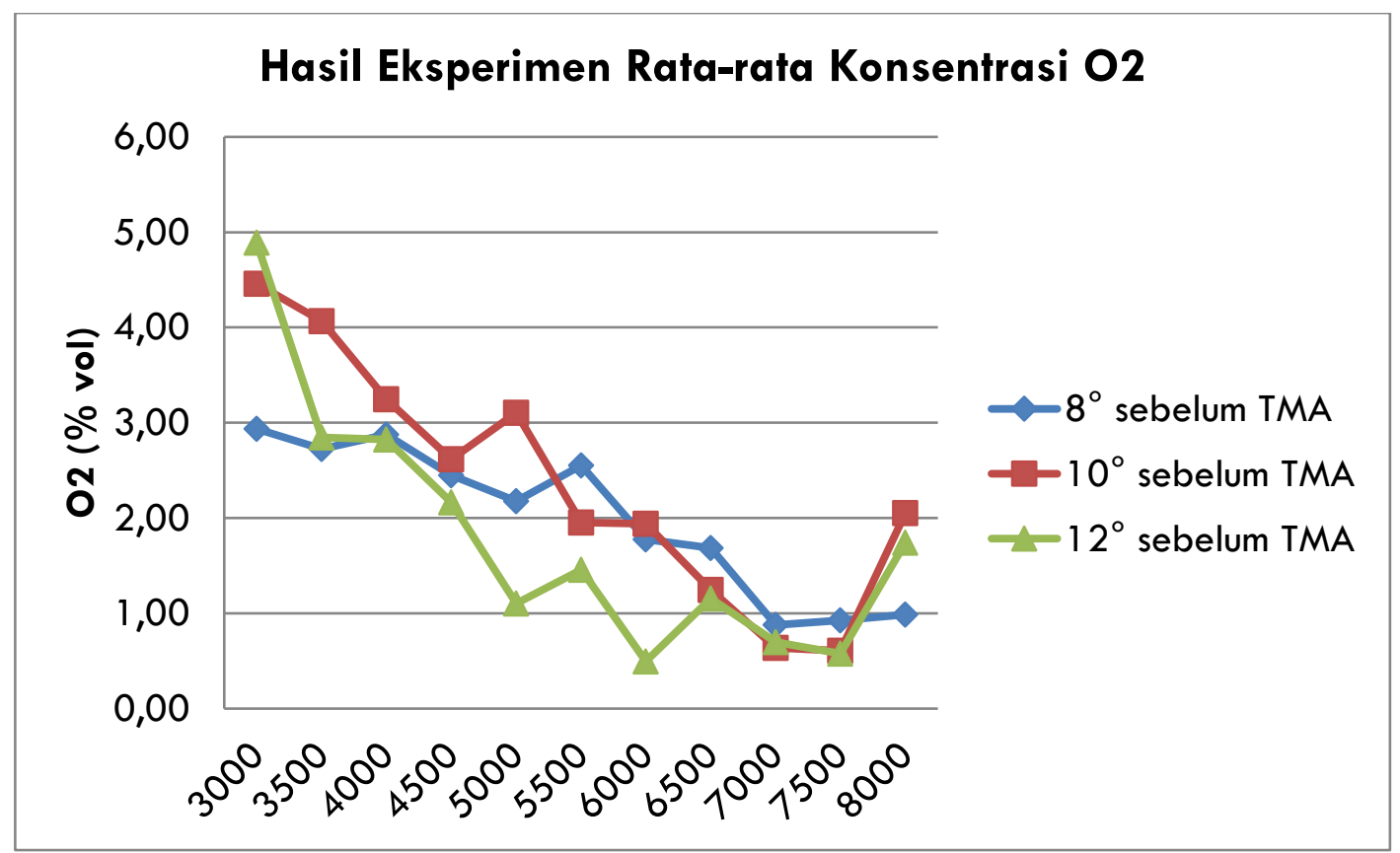

Gambar 6. Grafik Hasil Eksperimen Rata-rata Konsentrasi Oksigen $\left(\mathrm{O}_{2}\right)$ dalam \%vol

Dengan memperhatikan grafik pada gambar 6 , konsentrasi $\mathrm{O}_{2}$ pada setiap variasi waktu pengapian mengalami perubahan seiring putaran mesin yang semakin meningkat. Kadar $\mathrm{O}_{2}$ tertinggi sebesar 4,89\%vol terjadi pada waktu pengapian $12^{0}$ sebelum TMA di putaran mesin $6000 \mathrm{rpm}$.

\section{Hasil Eksperimen Rata-rata Torsi (T) dalam kgf.m}

Dari hasil percobaan modifikasi waktu pengapian, maka diperoleh tabel nilai Torsi (T), adalah sebagai berikut:

Tabel 5. Hasil Eksperimen Rata-rata Nilai Torsi (T) dalam kgf.m

\begin{tabular}{|c|c|c|c|}
\hline \multirow{2}{*}{ Putaran (rpm) } & \multicolumn{3}{|c|}{ Torsi (T) } \\
\cline { 2 - 4 } & $8^{\circ}$ sebelum TMA & $10^{\circ}$ sebelum TMA & $12^{\circ}$ sebelum TMA \\
\hline 3000 & 0.44 & 0.35 & 0.45 \\
\hline 3500 & 0.73 & 0.76 & 0.79 \\
\hline 4000 & 0.73 & 0.78 & 0.80 \\
\hline 4500 & 0.74 & 0.78 & 0.81 \\
\hline 5000 & 0.73 & 0.77 & 0.83 \\
\hline 5500 & 0.72 & 0.80 & 0.77 \\
\hline 6000 & 0.76 & 0.77 & 0.79 \\
\hline
\end{tabular}




\begin{tabular}{|c|c|c|c|}
\hline \multirow{2}{*}{ Putaran (rpm) } & \multicolumn{3}{|c|}{ Torsi (T) } \\
\cline { 2 - 4 } & $8^{\circ}$ sebelum TMA & $10^{\circ}$ sebelum TMA & $12^{\circ}$ sebelum TMA \\
\hline 6500 & 0.74 & 0.77 & 0.78 \\
\hline 7000 & 0.72 & 0.77 & 0.76 \\
\hline 7500 & 0.71 & 0.74 & 0.75 \\
\hline 8000 & 0.65 & 0.69 & 0.65 \\
\hline
\end{tabular}

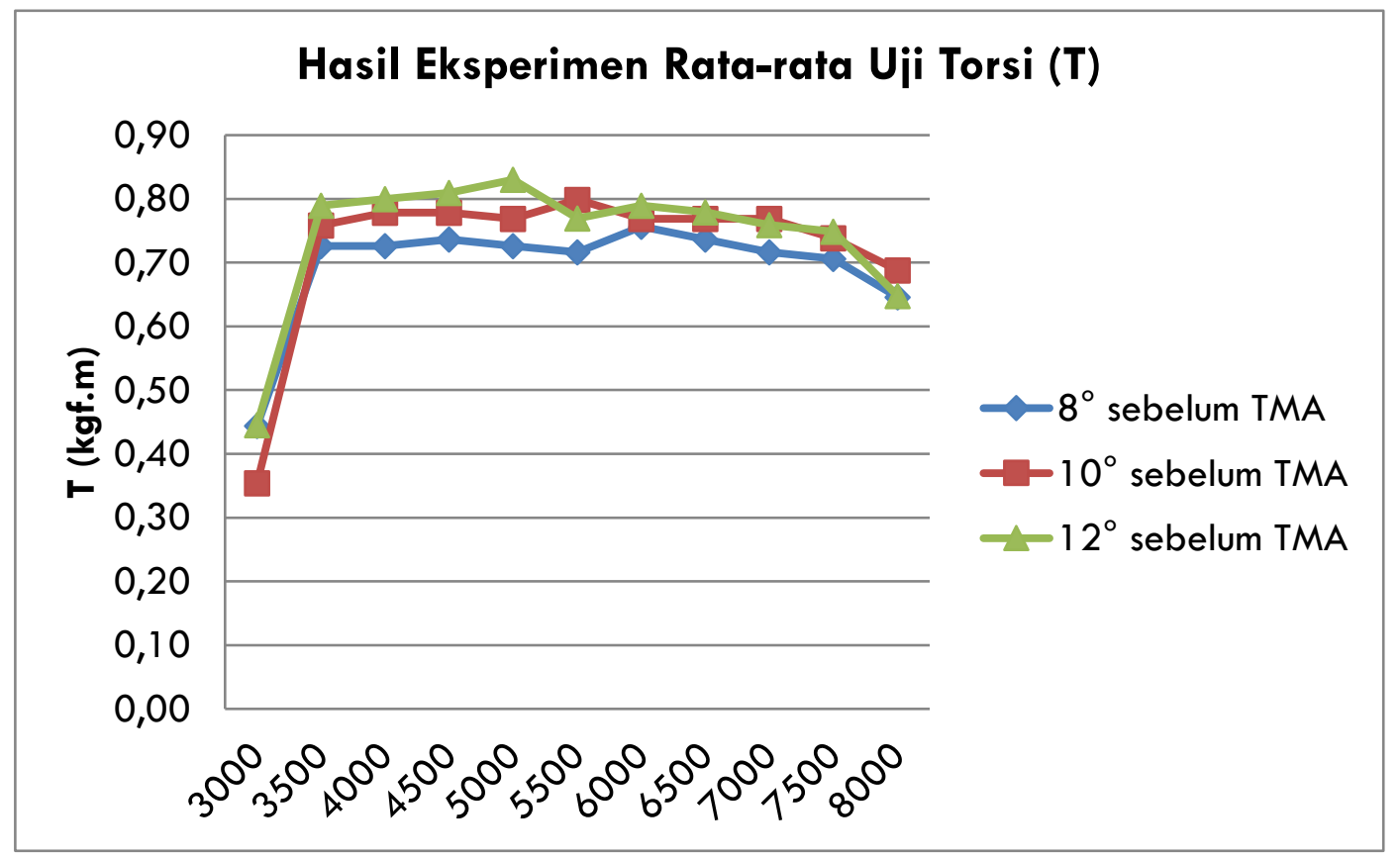

Gambar 7. Grafik Hasil Eksperimen Rata-rata Nilai Torsi (T) dalam kgf.m

Memperhatikan grafik yang ada pada gambar 7, nilai torsi pada setiap variasi waktu pengapian mengalami perubahan seiring putaran mesin yang semakin meningkat. Nilai torsi tertinggi sebesar $0,83 \mathrm{kgf} . \mathrm{m}$ terjadi pada waktu pengapian $12^{0}$ sebelum TMA di putaran mesin $5000 \mathrm{rpm}$.

Pada range putaran mesin 5000 s/d $6000 \mathrm{rpm}$ di semua variasi pengapian terdapat peningkatan torsi. Hal ini dikarenakan temperatur campuran udara dan bahan bakar yang tercapai pada masing-masing waktu pengapian ideal pada putaran $5000 \mathrm{~s} / \mathrm{d} 6000 \mathrm{rpm}$, sehingga torsi yang dihasilkan maksimal. 


\section{Hasil Eksperimen Rata-rata Daya Efektif (P) dalam PS}

Dari hasil percobaan modifikasi waktu pengapian, maka diperoleh tabel nilai Daya Efektif (P), adalah sebagai berikut:

Tabel 6. Hasil Eksperimen Rata-rata Nilai Daya Efektif (P) dalam PS

\begin{tabular}{|c|c|c|c|}
\hline \multirow{2}{*}{ Putaran (rpm) } & \multicolumn{3}{|c|}{ Daya Efektif (P) } \\
\cline { 2 - 4 } & $8^{\circ}$ sebelum TMA & $10^{\circ}$ sebelum TMA & $12^{\circ}$ sebelum TMA \\
\hline 3000 & 1.88 & 1.54 & 1.88 \\
\hline 3500 & 3.58 & 3.93 & 4.48 \\
\hline 4000 & 4.06 & 4.31 & 4.83 \\
\hline 4500 & 4.64 & 4.88 & 5.10 \\
\hline 5000 & 5.11 & 5.37 & 5.58 \\
\hline 5500 & 5.53 & 5.85 & 5.65 \\
\hline 6000 & 6.27 & 6.49 & 6.60 \\
\hline 6500 & 6.72 & 7.04 & 7.05 \\
\hline 7000 & 7.23 & 7.34 & 7.46 \\
\hline 7500 & 7.46 & 7.41 & 7.63 \\
\hline 8000 & 7.43 & 7.39 & 7.32 \\
\hline
\end{tabular}

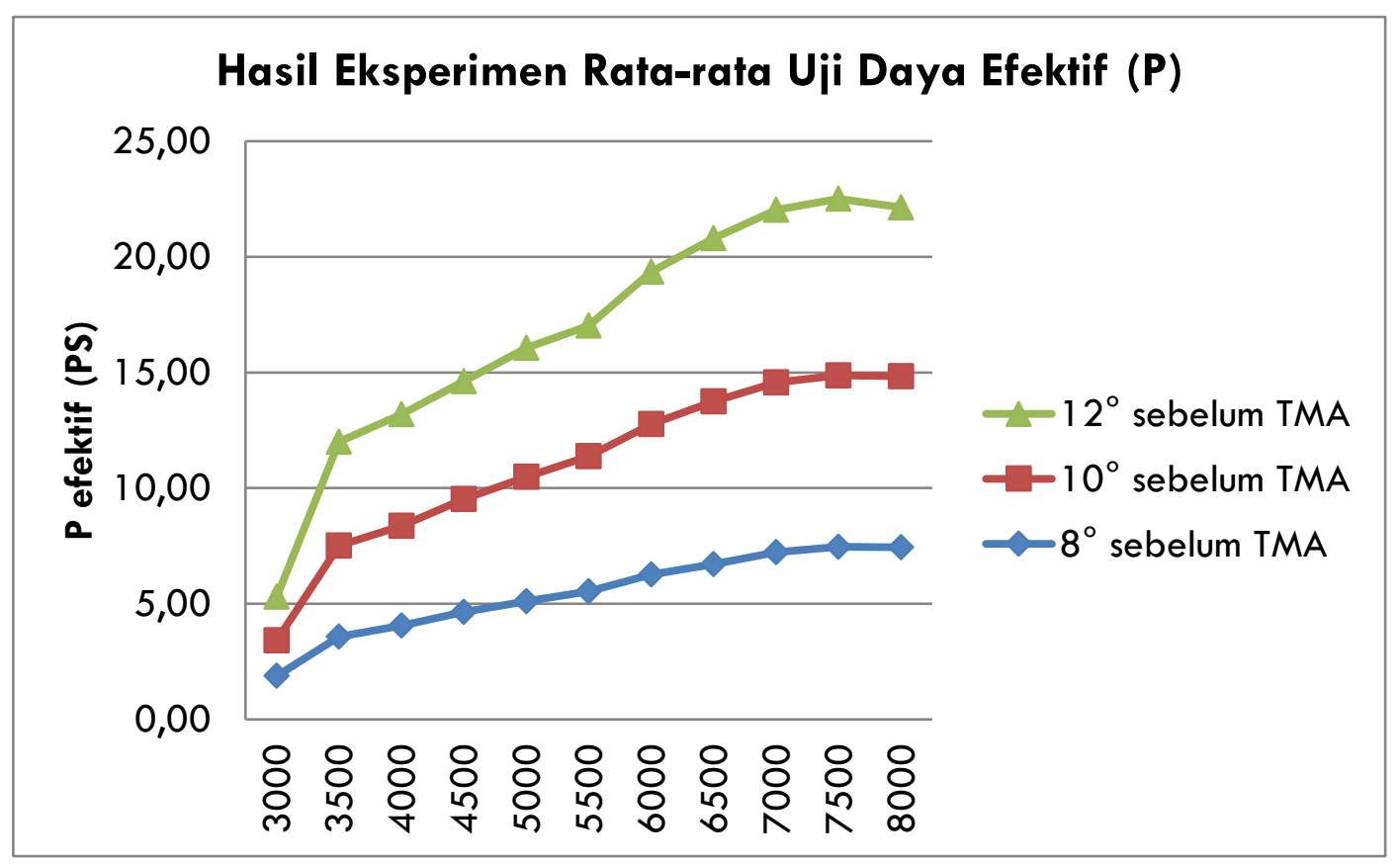

Gambar 8. Grafik Hasil Eksperimen Rata-rata Nilai Daya Efektif (P) dalam PS 
Dengan memperhatikan grafik pada gambar 8 , nilai daya pada setiap variasi waktu pengapian mengalami perubahan seiring putaran mesin yang semakin meningkat. Nilai daya tertinggi sebesar 7,63 PS terjadi pada waktu pengapian $12^{0}$ sebelum TMA di putaran mesin $7500 \mathrm{rpm}$.

Penyalaan busi yang baik bergantung pada kecepatan perambatan nyala, temperatur campuran udara bahan bakar yang ideal $\left(60^{\circ}\right)$ dan kecepatan putar poros engkol. Terjadi perbedaan tekanan dalam masing-masing posisi penyalaan busi, dipengaruhi oleh waktu penyalaan busi itu sendiri, baik pada putaran mesin rendah maupun putaran mesin tinggi.

Penggunaan variasi bahan bakar $\mathrm{E}_{10}$ berpengaruh terhadap kinerja mesin dengan meningkatkan temperatur bahan bakar pada intake manifold, sehingga campuran udara dan bahan bakar dapat berubah menjadi gas, agar bahan bakar yang masuk ke dalam ruang bakar menjadi optimal dan menghasilkan daya $\mathrm{P}$ (ledakan) yang besar.

\section{KESIMPULAN DAN SARAN}

\section{Kesimpulan}

a. Pada putaran mesin $8000 \mathrm{rpm}$ di semua variasi waktu pengapian, konsentrasi CO menunjukkan angka tertinggi. Dalam variasi waktu pengapian $10^{\circ}$ dan $12^{0}$ sebelum TMA nilai CO yang dihasilkan yaitu 4,56 \%vol dan 6,44 \%vol, melebihi ambang batas yang ditentukan sebesar 4,5 \%vol. Kadar CO semakin menurun di bawah ambang batas pada range putaran mesin 3000 sampai $7500 \mathrm{rpm}$.

b. Kadar CO2 terendah sebesar 9,40\%vol terjadi pada waktu pengapian $12^{0}$ sebelum TMA di putaran mesin 8000 rpm. Kenaikan putaran mesin mempercepat proses pembakaran, maka bahan bakar yang terbakar relatif lebih banyak dan konsentrasi CO2 cenderung semakin kecil. Hal tersebut dikarenakan penggunaan variasi bahan bakar $\mathrm{E}_{10}$. 
c. Kadar HC terendah sebesar $62,45 \mathrm{ppm}$ vol terjadi pada waktu pengapian $8^{0}$ sebelum TMA di putaran mesin $6500 \mathrm{rpm}$. Pada putaran mesin menengah (5000 s/d 6500 rpm), emisi HC mengalami penurunan yang signifikan. Hal ini disebabkan karena campuran udara dan bahan bakar mendekati stoichiometric dengan adanya penggunaan variasi bahan bakar $\mathrm{E}_{10}$. Sehingga, bahan bakar berubah fasenya menjadi gas, maka mudah untuk terbakar di ruang bakar.

d. Kadar $\mathrm{O}_{2}$ tertinggi sebesar $4,89 \%$ vol terjadi pada waktu pengapian $12^{0}$ sebelum TMA di putaran mesin $6000 \mathrm{rpm}$.

e. Nilai torsi tertinggi sebesar $0,83 \mathrm{kgf} . \mathrm{m}$ terjadi pada waktu pengapian $12^{0}$ sebelum TMA di putaran mesin $5000 \mathrm{rpm}$. Pada range putaran mesin 5000 s/d $6000 \mathrm{rpm}$ di semua variasi pengapian terdapat peningkatan torsi. Hal ini dikarenakan temperatur campuran udara dan bahan bakar yang tercapai pada masing-masing waktu pengapian ideal pada putaran 5000 s/d 6000 rpm, sehingga torsi yang dihasilkan maksimal.

f. Nilai daya tertinggi sebesar 7,63 PS terjadi pada waktu pengapian $12^{0}$ sebelum TMA di putaran mesin $7500 \mathrm{rpm}$. Penggunaan variasi bahan bakar $\mathrm{E}_{10}$ berpengaruh terhadap kinerja mesin dengan meningkatkan temperatur bahan bakar pada intake manifold, sehingga campuran udara dan bahan bakar dapat berubah menjadi gas, agar bahan bakar yang masuk ke dalam ruang bakar menjadi optimal dan menghasilkan daya $\mathrm{P}$ (ledakan) yang besar.

\section{Saran}

a. Bagi pembaca yang akan mengaplikasikan penelitian ini dalam kehidupan sehari-hari sebaiknya memodifikasi waktu pengapian menjadi $8^{0}$ sebelum TMA, untuk mendapatkan kadar emisi CO dan HC yang rendah.

b. Bagi pembaca yang akan melakukan penelitian serupa hendaknya memodifikasi mesin pada bagian sistem bahan bakar, sistem pengapian, 
dan konstruksi mesin agar campuran bahan bakar dapat tercampur secara homogen, ionisasi sempurna, dan pengapian sempurna.

c. Perlu diadakan penelitian lebih lanjut agar dapat menciptakan alat untuk menjaga temperatur udara dan bahan bakar dalam intake manifold, agar dapat terjaga pada suhu $60^{\circ}$.

\section{DAFTAR PUSTAKA}

Arismunandar, W., 2002, Motor Bakar Torak, Edisi 5, ITB, Bandung.

Arends, BPM, Berenschot, H.,1980, (Alih Bahasa), Motor Bensin, PT. Erlangga, Jakarta.

Heywood, JB., 1988, Internal Combustion Engine Fundamentals, McGraw-Hill, Inc., USA.

Anonim, Manual Book Sepeda Motor Honda Vario, Astra Honda Motor, 2011.

Edward F. Obert, Internal Combustion Engines and Air Pollution, Harper \& Row, Publishers, Inc, 1973.

Erliza Hambali, Siti Mujdalipah, Armansyah Halomoan Tambunan, Abdul Waries Pattiwiri, dan Roy Hendroko.2007. Teknologi Bioenergi. Jakarta: Agromedia Pustaka.

Kusminingrum Nanny dan G. Gunawan. 2008. Polusi Udara Akibat Aktivitas Kendaraan Bermotor di Jalan Perkotaan Pulau Jawa dan Bali.Bandung : Puslitbang Jalan dan Jembatan.

Michael J Moran dan Howard Shapiro, TermodinamikaTeknik 1, Erlangga.

PT. Astra Daihatsu Motor Training Center, Diktat VVT-i, Jakarta, 2008.

Pulkrabek Willard W, Engineering Fundamentals of The Internal Combustion Engine, Prentice Hall, New Jersey.

Saeful Rokhim, ST, MT dan team PPPTK (Pusat Pengembangan Dan Pemberdayaan Pendidik Dan Tenaga Kependidikan Bidang Otomotif \& Elektronika Malang)

- VEDC (Vocational Education Development Center), Modul Dasar Motor, Malang, 2011 